Research Paper

\title{
Unresolved Subclinical Hypothyroidism is Independently Associated with Progression of Chronic Kidney Disease
}

\author{
Eun Oh Kim¹, Ihn Suk Lee², Yoo A Choi ${ }^{1}$, Sang Ju Lee1, Yoon Kyung Chang1, Hye Eun Yoon', Yi Sun Jang², \\ Jong Min Lee ${ }^{2}$, Hye Soo Kim², Chul Woo Yang${ }^{1}$, Suk Young Kim ${ }^{1}$, Hyeon Seok Hwang ${ }^{\circledR}$ \\ 1. Division of Nephrology, Departments of Internal Medicine, The Catholic University of Korea, Seoul, Korea \\ 2. Division of Endocrinology, Departments of Internal Medicine, The Catholic University of Korea, Seoul, Korea \\ $\triangle$ Corresponding author: Hyeon Seok Hwang, MD, PhD, Division of Nephrology, Department of Internal Medicine, Daejeon St. Mary's Hospital, \\ 520-2Daeheung-Dong, Jung-Ku, 301-804, Daejeon, Korea. Phone: +82-42-220-9335, Fax: +82-42-220-9669; E-mail: hwanghs@catholic.ac.kr
}

(c) Ivyspring International Publisher. This is an open-access article distributed under the terms of the Creative Commons License (http://creativecommons.org/ licenses/by-nc-nd/3.0/). Reproduction is permitted for personal, noncommercial use, provided that the article is in whole, unmodified, and properly cited.

Received: 2013.07.18; Accepted: 2013.12.11; Published: 2013.12.20

\begin{abstract}
Background and Aim: Patients with chronic kidney disease (CKD) often have subclinical hypothyroidism. However, few reports have investigated changes in the status of subclinical hypothyroidism in CKD patients and its clinical significance in CKD progression.

Methods: We included 168 patients with nondialysis-dependent CKD stages 2-4. The normalization of subclinical hypothyroidism during follow-up was assessed, and the association between transitions in subclinical hypothyroid status and the rate of decline of the estimated glomerular filtration rate (eGFR) was investigated.

Results: At baseline, I 27 patients were euthyroid and 4I (24.4\%) patients were diagnosed with subclinical hypothyroidism. Of these $4 \mathrm{I}$ patients, 2 I (5I.2\%) spontaneously resolved to euthyroid during follow-up. The rate of eGFR decline of patients with resolved subclinical hypothyroidism was similar to that of euthyroid patients. The patients with unresolved subclinical hypothyroidism showed a steeper renal function decline than patients with euthyroidism or resolved subclinical hypothyroidism (all $p<0.05$ ). The progression to end-stage renal disease was more frequent in those with unresolved subclinical hypothyroidism than in those who were euthyroid $(p=0.006)$. In multivariate linear regression for rate of eGFR decrease, unresolved subclinical hypothyroidism $(\beta$ $=-5.77, \mathrm{p}=0.00 \mathrm{I})$, baseline renal function $(\beta=-0.12, \mathrm{p}<0.00 \mathrm{I})$ and level of proteinuria $(\beta=$ $-2.36, p=0.015)$ were independently associated with the rate of renal function decline.

Conclusions: Half of the CKD patients with subclinical hypothyroidism did not resolve to euthyroidism, and this lack of resolution was independently associated with rapid renal function decline.
\end{abstract}

Key words: chronic kidney disease, progression, subclinical hypothyroidism.

\section{Introduction}

Changes in thyroid hormones are common in patients with chronic kidney disease (CKD), and the prevalence of thyroid dysfunction increases as CKD progresses $(1,2)$. Thyroid hormones affect nearly every organ system in the body, and are associated with many of the components contributing to kidney disease. Hypothyroidism is associated with reduced renal plasma flow, low glomerular filtration rate, decreased sodium reabsorption and the inability to dilute urine (3). Thyroid hormones have multiple protective effects on renal function, so replacement ther- apy can reverse the deterioration of renal function in hypothyroid patients (4-6).

The concept of subclinical hypothyroidism has emerged as our ability to detect subtle changes in thyroid function has progressively improved. Subclinical hypothyroidism, defined as elevated serum thyrotropin (TSH) but normal free T4 levels, is frequently observed in patients with CKD and has a number of clinical implications. Subclinical hypothyroidism is linked to inflammation and predicts all-cause mortality in patients on continuous ambu- 
latory peritoneal dialysis (7). It was also identified as a risk factor for nephropathy and cardiovascular events in patients with type 2 diabetes (8). However, relatively little is known about the clinical impacts of subclinical hypothyroidism on progression of nondialysis-dependent CKD. Furthermore, few reports investigate the resolution of subclinical hypothyroidism in patients with CKD, although $10 \%-40 \%$ of the general population with subclinical hypothyroidism spontaneously normalize their TSH values early in the follow-up $(9,10)$.

Therefore, we aimed to assess the rate of spontaneous resolution of subclinical hypothyroidism in patients with CKD not requiring dialysis, and to determine whether the transitions in subclinical hypothyroidism influenced the rate of renal function decline. In addition, we attempted to investigate whether subclinical hypothyroidism was an independent determinant for progression of CKD.

\section{Methods}

\section{Patients}

This study was approved by the Institutional Review Board of our center (DC12RISI0077). We included all patients at Daejeon St. Mary's Hospital from January 2005 to March 2012 with nondialysis-dependent CKD stages 2-4 who were evaluated for thyroid function. The estimated glomerular filtration rate (eGFR) was calculated using the abbreviated Modification of Diet in Renal Disease formula, and the stages of CKD were defined according to the American National Kidney Foundation: stage 2, eGFR 60-89 $\mathrm{ml} / \mathrm{min} / 1.73 \mathrm{~m}^{2}$; stage 3 , eGFR $30-59 \mathrm{ml} / \mathrm{min} / 1.73$ $\mathrm{m}^{2}$; and stage $4,15-29 \mathrm{ml} / \mathrm{min} / 1.73 \mathrm{~m}^{2}(11,12)$. A total of 203 patients were screened, and to allow us to concentrate on subclinical hypothyroidism, 35 were excluded for the following reasons: hyperthyroidism $(\mathrm{n}=13)$, already on thyroid hormone treatment $(\mathrm{n}=$ $15)$, chromosomal disorder $(n=1)$, single kidney $(n=$ $2)$, and incomplete medical records $(n=4)$. We finally enrolled 168 patients in this study. Patients were followed from the time of thyroid evaluation to the date of permanent renal replacement therapy, patient death or follow up loss. No patient received L-thyroxine during the study period or had a follow-up duration of less than 6 months.

\section{Collection of demographic, medical, and laboratory data}

Demographic and clinical data at the time of diagnosis of thyroid status, including age, sex, body height and weight, and comorbidities, were recorded. The body mass index (BMI) was calculated as the ratio of weight in kilograms divided by square of height in meters. Mean arterial pressure (MAP) was defined as the diastolic pressure (in $\mathrm{mmHg}$ ) plus one third of the pulse pressure. The results of the following laboratory tests performed concurrently were collected: hemoglobin, white blood cell, differential counts (neutrophil, lymphocyte), serum creatinine, calcium, phosphate, total cholesterol, triglyceride, and low-density lipoprotein (LDL) cholesterol levels, and high sensitivity C-reactive protein (hsCRP). The results of hsCRP were known in 106 (63.1\%) of the 168 patients. Protein excretion/day was transformed to a protein-to-creatinine ratio. The neutrophil to lymphocyte ratio was constructed by dividing neutrophil count to lymphocyte count, which was another marker for inflammatory status in CKD patients (13). Because the distribution of proteinuria values and neutrophil to lymphocyte ratio was skewed, log-transformed values were used in the regression analysis. The echocardiographic data was collected in $77(45.8 \%)$ patients. The ejection fraction and left ventricular (LV) mass index was investigated, which was relevant with CKD progression (14). LV mass was calculated using following formulae: $\mathrm{LV}$ mass $=0.8 \times[1.04 \times$ (left ventricular end-diastolic diameter + diastolic posterior wall thickness + diastolic septal wall thickness) ${ }^{3}-($ left ventricular end-diastolic diameter) $\left.{ }^{3}\right]+0.6$ (15) . LV mass index was calculated by dividing left ventricular mass by body surface area. End-stage renal disease (ESRD) was defined as an eGFR of less than 15 $\mathrm{mL} / \mathrm{min}$ per $1.73 \mathrm{~m}^{2}$ or a condition requiring long-term renal replacement therapy. The rate of renal function decline in each patient was assessed by the slope of eGFR decline, defined as the regression coefficient between eGFR and time in units of $\mathrm{ml} / \mathrm{min} / 1.73 \mathrm{~m}^{2} /$ year.

\section{Thyroid function test and definitions}

In all patients, serum T3, free T4 and TSH were measured. Thyroid function tests were performed by chemiluminescence immunoassay using the Modular Analytics E170 immunoassay analyzer (Roche Diagnostics, Basel, Switzerland). The diagnosis of subclinical hypothyroidism was based upon the results of a thyroid function test and was defined as normal serum free T4 but elevated TSH levels, irrespective of clinical symptoms of hypothyroidism. The reference ranges for T3, free T4, and TSH were 1.16-2.87 $\mathrm{nmol} / \mathrm{l}, 0.93-1.70 \mathrm{ng} / \mathrm{dl}$ and $0.27-4.20 \mu \mathrm{IU} / \mathrm{ml}$, respectively. The intra-assay coefficient of variation for these hormones ranged, respectively, from $1.5 \%$ to $3.1 \%$ for $\mathrm{T} 3,1.4 \%$ to $2.0 \%$ for free $\mathrm{T} 4$ and $3.0 \%$ to $1.1 \%$ for TSH. The thyroid function at follow-up was evaluated to allow assessment of the normalization of subclinical hypothyroidism. 


\section{Statistical analysis}

The statistical analysis was performed using the SPSS v. 16.0 software package (IBM, Armonk, NY, USA). Data are expressed as mean \pm SD or proportions. Differences in continuous variables were compared using Student's $t$ test or the Mann-Whitney $U$ test, and differences in categorical variables were compared using the $\chi^{2}$ test or Fisher's exact test as appropriate. Statistical differences between parametric variables of the three groups were analyzed using the one-way ANOVA or Kruskal-Wallis test, and the differences between subgroups were assessed with the post hoc Tukey test. A multivariate linear regression test was used to determine the independent factors affecting the rate of renal function decline, and included all covariates with a $p$ value less than 0.1 on univariate analysis and with clinical significance. A p value $<0.05$ was considered to be statistically significant.

\section{Results}

\section{Baseline characteristics}

Subclinical hypothyroidism was detected in 41 $(24.4 \%)$ patients, and $21(51.2 \%)$ of these showed a return to normal thyroid function during follow-up. The baseline demographic and clinical characteristics of the study subjects, stratified by thyroid status, are listed in Table 1. Age, proportion of men, BMI, blood pressure, baseline laboratory data including eGFR, hsCRP and neutrophil to lymphocyte ratio did not differ between the three thyroid status groups. The number of antihypertensive drugs and the use of angiotensin-converting enzyme inhibitor or angiotensin II receptor blocker also did not differ between groups. The patients with unresolved subclinical hypothyroidism revealed the ejection fraction of $61.9 \pm 14.9 \%$ and LV mass index of $87.2 \pm 40.6 \mathrm{~g} / \mathrm{m}^{2}$, which was not different from euthyroid patients or those with resolved subclinical hypothyroidism (Supplementary material: Table S1).

Table I. Baseline demographic, clinical and biochemical characteristics of the subjects

\begin{tabular}{|c|c|c|c|c|c|}
\hline & $\begin{array}{l}\text { Total } \\
(n=168)\end{array}$ & $\begin{array}{l}\text { Unresolved subclinical hy- } \\
\text { pothyroidism } \\
(\mathrm{n}=20)\end{array}$ & $\begin{array}{l}\text { Resolved subclinical } \\
\text { hypothyroidism } \\
(\mathrm{n}=21)\end{array}$ & $\begin{array}{l}\text { Euthyroid } \\
(\mathrm{n}=127)\end{array}$ & $\mathbf{p}$ \\
\hline Age (years) & $64.8 \pm 14.6$ & $63.8 \pm 17.2$ & $62.3 \pm 19.6$ & $65.4 \pm 13.7$ & 0.639 \\
\hline Male (\%) & $88(52.4)$ & $8(40.0)$ & $11(52.4)$ & $69(54.3)$ & 0.491 \\
\hline BMI $\left(\mathrm{kg} / \mathrm{m}^{2}\right)$ & $23.9 \pm 5.0$ & $22.2 \pm 7.0$ & $23.7 \pm 3.3$ & $24.2 \pm 4.9$ & 0.267 \\
\hline SBP (mmHg) & $123.2 \pm 13.9$ & $119.4 \pm 12.6$ & $127.5 \pm 14.1$ & $123.0 \pm 14.0$ & 0.199 \\
\hline DBP (mmHg) & $76.3 \pm 8.2$ & $74.4 \pm 6.2$ & $78.8 \pm 9.4$ & $76.1 \pm 8.3$ & 0.255 \\
\hline MAP (mmHg) & $91.9 \pm 9.5$ & $89.4 \pm 7.5$ & $95.0 \pm 10.6$ & $91.7 \pm 9.5$ & 0.186 \\
\hline \multicolumn{6}{|l|}{ Comorbidities } \\
\hline Diabetes (\%) & $73(43.5)$ & $13(65.0)$ & $6(28.6)$ & $54(42.5)$ & 0.057 \\
\hline Coronary artery disease (\%) & $30(17.9)$ & $4(20.0)$ & $7(33.3)$ & $19(15.0)$ & 0.140 \\
\hline Heart failure (\%) & $13(7.7)$ & $3(15.0)$ & $2(9.5)$ & $8(6.3)$ & 0.403 \\
\hline Cerebrovascular disease (\%) & $29(17.3)$ & $4(20.0)$ & $4(19.0)$ & $21(16.5)$ & 0.943 \\
\hline Liver cirrhosis $(\%)$ & $7(4.2)$ & $1(5.0)$ & 0 & $6(4.7)$ & 0.674 \\
\hline COPD $(\%)$ & $5(3.0)$ & 0 & 0 & $5(3.9)$ & 0.463 \\
\hline Autoimmune disease (\%) & $3(1.8)$ & 0 & 0 & $3(2.4)$ & 1.00 \\
\hline eGFR (ml/min/1.73 m²) & $41.4 \pm 16.1$ & $37.9 \pm 18.6$ & $38.8 \pm 14.9$ & $42.4 \pm 15.9$ & 0.370 \\
\hline CKD stage & & & & & 0.592 \\
\hline Stage $2(\%)$ & $21(12.5)$ & $2(10.0)$ & $1(4.8)$ & $18(14.2)$ & \\
\hline Stage $3(\%)$ & $98(58.3)$ & $10(50.0)$ & $13(61.9)$ & $75(59.1)$ & \\
\hline Stage $4(\%)$ & $49(29.2)$ & $8(40.0)$ & $7(33.3)$ & $34(26.8)$ & \\
\hline \multicolumn{6}{|l|}{ Laboratory data } \\
\hline Hemoglobin (g/dL) & $12.0 \pm 2.1$ & $11.3 \pm 0.9$ & $11.5 \pm 2.3$ & $12.1 \pm 2.2$ & 0.173 \\
\hline Calcium (mg/dL) & $9.0 \pm 0.8$ & $9.2 \pm 1.4$ & $8.7 \pm 0.9$ & $9.0 \pm 0.6$ & 0.091 \\
\hline Phosphorus (mg/dL) & $3.7 \pm 0.9$ & $3.9 \pm 1.1$ & $3.7 \pm 0.9$ & $3.7 \pm 0.8$ & 0.467 \\
\hline Total cholesterol (mg/dL) & $178.9 \pm 58.2$ & $189.9 \pm 38.7$ & $181.5 \pm 106.0$ & $176.9 \pm 49.8$ & 0.661 \\
\hline Triglyceride (mg/dL) & $174.9 \pm 113.1$ & $179.7 \pm 92.6$ & $145.9 \pm 82.0$ & $178.8 \pm 119.8$ & 0.476 \\
\hline $\mathrm{LDL}(\mathrm{mg} / \mathrm{dL})$ & $101.8 \pm 49.8$ & $107.2 \pm 38.3$ & $111.3 \pm 90.8$ & $99.6 \pm 42.2$ & 0.587 \\
\hline Albumin (g/dL) & $3.9 \pm 0.7$ & $3.7 \pm 0.7$ & $3.7 \pm 0.8$ & $4.0 \pm 0.7$ & 0.112 \\
\hline hsCRP (mg/dL)* & $2.5 \pm 6.1$ & $2.0 \pm 4.9$ & $2.6 \pm 5.8$ & $2.6 \pm 6.4$ & 0.722 \\
\hline Neutrophil to lymphocyte ratio & $3.3 \pm 3.2$ & $2.8 \pm 2.2$ & $3.4 \pm 3.0$ & $2.3 \pm 3.3$ & 0.713 \\
\hline \multicolumn{6}{|l|}{ Medications } \\
\hline $\begin{array}{l}\text { Number of } \\
\text { anti-hypertensive drugs }\end{array}$ & $2.0 \pm 1.3$ & $1.9 \pm 1.2$ & $2.4 \pm 1.5$ & $1.9 \pm 1.3$ & 0.354 \\
\hline ACEi or ARB use (\%) & $100(60.6)$ & $10(52.6)$ & $15(71.4)$ & $75(60.0)$ & 0.459 \\
\hline
\end{tabular}


Table 2. Comparison of thyroid function tests and proteinuria amount between CKD patients with different thyroid status

\begin{tabular}{|c|c|c|c|c|}
\hline & $\begin{array}{l}\text { Unresolved subclinical hy- } \\
\text { pothyroidism }\end{array}$ & $\begin{array}{l}\text { Resolved subclinical hypo- } \\
\text { thyroidism }\end{array}$ & Euthyroid & $\mathbf{p}$ \\
\hline Follow up time (months) & $19.1 \pm 14.6^{*}$ & $31.6 \pm 23.8$ & $31.7 \pm 20.7$ & 0.039 \\
\hline \multicolumn{5}{|l|}{ Baseline } \\
\hline T3 (nmol/l) & $1.25 \pm 0.34$ & $1.36 \pm 0.42$ & $1.38 \pm 0.52$ & 0.631 \\
\hline free T4 (ng/dl) & $1.19 \pm 0.20$ & $1.21 \pm 0.16$ & $1.25 \pm 0.21$ & 0.355 \\
\hline $\mathrm{TSH}(\mu \mathrm{IU} / \mathrm{ml})$ & $7.47 \pm 3.61^{*}, \dagger$ & $6.27 \pm 1.42 \dagger$ & $1.79 \pm 0.96$ & $<0.001$ \\
\hline Proteinuria (g/day) & $2.63 \pm 3.8$ & $2.17 \pm 2.68$ & $1.38 \pm 2.04$ & 0.119 \\
\hline \multicolumn{5}{|l|}{ At the end of follow up } \\
\hline T3 (nmol/1) & $1.10 \pm 0.17$ & $1.10 \pm 0.27$ & $1.24 \pm 0.35$ & 0.172 \\
\hline free T4 $(\mathrm{ng} / \mathrm{dl})$ & $1.17 \pm 0.29$ & $1.23 \pm 0.30$ & $1.26 \pm 0.29$ & 0.595 \\
\hline $\mathrm{TSH}(\mu \mathrm{IU} / \mathrm{ml})$ & $9.84 \pm 21.4^{*}, \dagger$ & $2.32 \pm 1.00$ & $1.72 \pm 1.32$ & 0.001 \\
\hline Proteinuria (g/day) & $1.99 \pm 2.41$ & $1.77 \pm 2.61$ & $1.32 \pm 1.97$ & 0.218 \\
\hline
\end{tabular}

Abbreviations: TSH, serum thyrotropin .

${ }^{*} \mathrm{p}<0.05$ vs. euthyroid, ${ }^{\dagger} \mathrm{p}<0.05$ vs. resolved subclinical hypothyroidism.

\section{Changes in subclinical hypothyroidism during follow-up}

The results of thyroid function tests at baseline and the end of follow-up are listed in Table 2. The average baseline TSH level was $7.47 \pm 3.61 \mu \mathrm{IU} / \mathrm{ml}$ in patients with unresolved subclinical hypothyroidism, significantly higher than in patients with resolved subclinical hypothyroidism or euthyroid patients (all $p<0.05)$. The patients with resolved subclinical hypothyroidism showed a higher level of baseline TSH than euthyroid patients $(p<0.001)$, but this was restored to normal during follow-up. In contrast, the TSH level in patients with unresolved subclinical hypothyroidism became progressively higher during follow-up. Of the patients with unresolved subclinical hypothyroidism, overt hypothyroidism developed in six $(14.6 \%)$ patients, and $14(34.3 \%)$ patients still showed subclinical hypothyroidism at the end of follow-up. The proteinuria amount was not different between three thyroid status groups at baseline or at the end of follow up.

\section{Clinical impacts of unresolved subclinical hypothyroidism on progression of CKD}

We compared the slope of eGFR decline between the three groups with different thyroid status (Fig. 1). The slope of eGFR decline was comparable in euthyroid patients and those with resolved subclinical hypothyroidism $(\mathrm{p}=0.971)$. The mean eGFR decline/year was $-11.00 \pm 13.05$ in patients with unresolved subclinical hypothyroidism, which was significantly greater than in euthyroid patients or those with resolved subclinical hypothyroidism (all p < 0.05). The eGFR decline rate before resolution of subclinical hypothyroidism was identified in 7 patients with resolved subclinical hypothyroidism, and it was similar to one of patients with unresolved subclinical hypothyroidism $\left(-11.7 \pm 13.8 \mathrm{ml} / \mathrm{min} / 1.73 \mathrm{~m}^{2} / \mathrm{yr} ; \mathrm{p}=\right.$ 0.907).

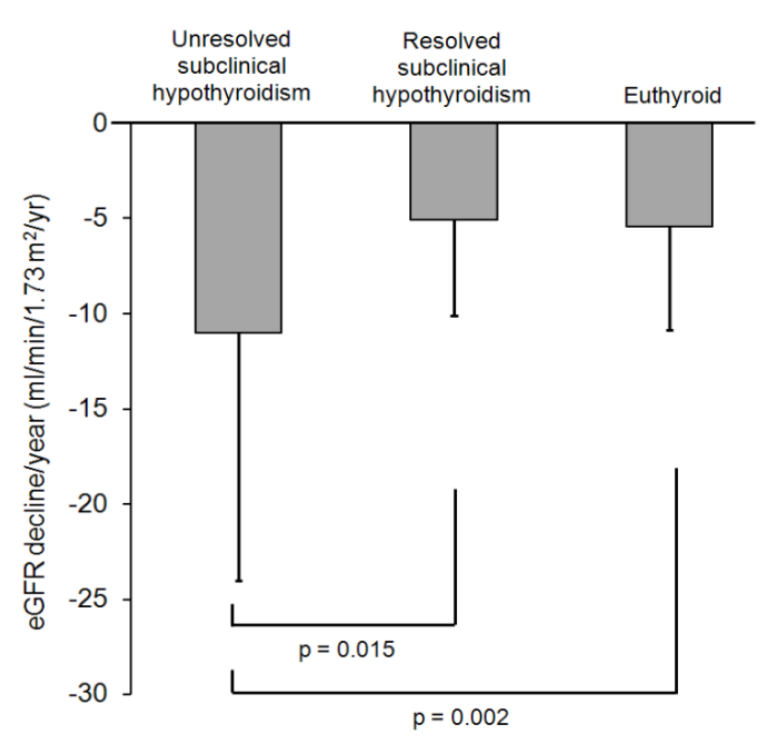

Figure I. Comparison of the slope of eGFR decline between CKD patients with different thyroid status. The rate of eGFR decline/year was significantly lower in patients with unresolved subclinical hypothyroidism than in patients with resolved subclinical hypothyroidism or euthyroidism.

We further evaluated the impact of unresolved subclinical hypothyroidisms on the rate of eGFR decline in each stage of CKD patients. The slope of eGFR decline was $-14.4 \pm 17.4$ in unresolved subclinical hypothyroid patients with CKD stage 3 , and it was significantly steeper than in euthyroid patients with CKD stage $3\left(-5.6 \pm 6.2 \mathrm{ml} / \mathrm{min} / 1.73 \mathrm{~m}^{2} / \mathrm{yr} ; \mathrm{p}=0.003\right)$ or resolved subclinical hypothyroid patients with CKD stage $3\left(-4.1 \pm 3.6 \mathrm{ml} / \mathrm{min} / 1.73 \mathrm{~m}^{2} / \mathrm{yr} ; \mathrm{p}=0.006\right)$. However, unresolved subclinical hypothyroid patients with CKD stage 4 did not show the steeper eGFR decline $\left(-6.5 \pm 4.5 \mathrm{ml} / \mathrm{min} / 1.73 \mathrm{~m}^{2} / \mathrm{yr}\right)$ than euthyroid $\left(-4.8 \pm 4.1 \mathrm{ml} / \mathrm{min} / 1.73 \mathrm{~m}^{2} / \mathrm{yr} ; \mathrm{p}=0.524\right)$ or resolved subclinical hypothyroid patients with CKD stage $4\left(-4.5 \pm 3.5 \mathrm{ml} / \mathrm{min} / 1.73 \mathrm{~m}^{2} / \mathrm{yr} ; \mathrm{p}=0.222\right)$.

The impact of unresolved subclinical hypothyroidisms on the rate of eGFR decline was also evalu- 
ated according to the degree of baseline proteinuria. Patients were classified into three groups: $<0.3 \mathrm{~g} /$ day proteinuria, 0.3-3 g/day and $>3 \mathrm{~g} /$ day (Supplementary material: Table S2). The slope of eGFR decline was $-12.3 \pm 7.7 \mathrm{ml} / \mathrm{min} / 1.73 \mathrm{~m}^{2} / \mathrm{yr}$ in unresolved subclinical hypothyroid patients with proteinuria < $0.3 \mathrm{~g} /$ day, and it was significantly steeper than in euthyroid patients with proteinuria $<0.3 \mathrm{~g} /$ day or resolved subclinical hypothyroid patients with proteinuria $<0.3 \mathrm{~g} /$ day (all $\mathrm{p}<0.05$ ). However, in patients with proteinuria $0.3-3 \mathrm{~g} /$ day or proteinuria $>3$ $\mathrm{g} /$ day, unresolved subclinical hypothyroid patients did not show steeper eGFR decline than euthyroid or resolved subclinical hypothyroid patients.

\section{Clinical impacts of unresolved subclinical hypothyroidism on ESRD}

We compared ESRD-free survival curves in the three thyroid status groups (Fig. 2). The 3-year ESRD-free survival rate was $81.8 \%$ and $74.2 \%$ in patients with euthyroidism and resolved subclinical hypothyroidism, respectively. Kaplan-Meier analysis showed that these were not different $(p=0.226)$. However, the patients with unresolved subclinical hypothyroidism demonstrated $64.5 \%$ ESRD-free sur- vival rate at 3-year follow-up, which was significantly lower than that of euthyroid patients $(p=0.006)$.

\section{Unresolved subclinical hypothyroidism is an independent risk factor for rapid renal function decline}

To identify the determinants of the rate of renal function decline measured by eGFR, clinical and laboratory parameters were entered in univariate and multivariate regression models (Table 3 ). Univariate analysis revealed that male sex, unresolved subclinical hypothyroidism, baseline eGFR, serum albumin level and proteinuria amount were significantly associated with the rate of eGFR decline/year. BMI and total cholesterol levels showed a marginally significant association with the rate of eGFR decline. In the multivariate analysis, the independent determinants for the rate of eGFR decline were unresolved subclinical hypothyroidism $(\beta=-5.77, \mathrm{p}=0.001)$, baseline eGFR $(\beta=-0.12, \mathrm{p}<0.001)$ and degree of proteinuria $(\beta=-2.36, \mathrm{p}=0.015)$. The overall model was significant $\left(R^{2}=0.206, \mathrm{p}<0.001\right)$, and unresolved subclinical hypothyroidism was the most important contributor to this significance.

Table 3. Determinants of the rate of eGFR slope in study patients

\begin{tabular}{|c|c|c|c|c|}
\hline & Univariate & & Multivariate & \\
\hline & $\begin{array}{l}\text { Unstandardized coefficient } \beta \\
(95 \% \mathrm{CI})\end{array}$ & $\mathrm{p}$ & $\begin{array}{l}\text { Unstandardized coefficient } \beta \\
(95 \% \mathrm{CI})\end{array}$ & $\mathrm{p}$ \\
\hline Age (years) & $0.03(-0.43,-0.10)$ & 0.422 & - & \\
\hline Male $(\%)$ & $2.44(0.34,4.53)$ & 0.023 & $1.30(-0.73,3.34)$ & 0.208 \\
\hline BMI (kg/m2) & $0.21(0.00,0.42)$ & 0.052 & $0.07(-0.14,0.29)$ & 0.500 \\
\hline Diabetes & $0.20(-2.03,2.26)$ & 0.913 & - & \\
\hline Coronary artery disease (\%) & $1.75(-1.01,4.51)$ & 0.212 & - & \\
\hline Heart failure $(\%)$ & $0.21(-3.78,4.18)$ & 0.919 & - & \\
\hline Cerebrovascular disease (\%) & $0.84(-1.97,3.65)$ & 0.556 & - & \\
\hline Liver cirrhosis $(\%)$ & $1.34(-3.97,6.65)$ & 0.619 & - & \\
\hline COPD $(\%)$ & $1.40(-4.85,7.65)$ & 0.659 & - & \\
\hline Autoimmune disease (\%) & $2.37(-5.65,10.39)$ & 0.560 & - & \\
\hline MAP (mmHg) & $-0.04(-0.15,0.08)$ & 0.518 & $-0.06(-0.18,0.05)$ & 0.268 \\
\hline Unresolved subclinical hypothyroidism & $-5.63(-8.79,-2.46)$ & 0.001 & $-5.77(-9.13,-2.42)$ & 0.001 \\
\hline $\operatorname{eGFR}\left(\mathrm{ml} / \mathrm{min} / 1.73 \mathrm{~m}^{2}\right)$ & $-0.10(-0.16,-0.03)$ & 0.003 & $-0.12(-0.19,-0.06)$ & $<0.001$ \\
\hline \multicolumn{5}{|l|}{ Laboratory data } \\
\hline Hemoglobin (g/dL) & $0.35(-0.16,0.85)$ & 0.174 & - & \\
\hline Calcium (mg/dL) & $0.92(-0.55,2.38)$ & 0.220 & - & \\
\hline Phosphorus (mg/dL) & $0.23(-1.09,1.55)$ & 0.730 & - & \\
\hline Total cholesterol (mg/dL) & $-0.02(-0.04,0.00)$ & 0.053 & $-0.01(-0.02,0.01)$ & 0.631 \\
\hline Triglyceride (mg/dL) & $0.00(-0.01,0.01)$ & 0.910 & - & \\
\hline $\mathrm{LDL}(\mathrm{mg} / \mathrm{dL})$ & $0.01(-0.03,0.04)$ & 0.808 & - & \\
\hline Albumin $(\mathrm{g} / \mathrm{dL})$ & $2.28(0.86,3.69)$ & 0.002 & $0.99(-0.61,2.59)$ & 0.223 \\
\hline Proteinuria (g/day) & $-2.81(-4.36,-1.27)$ & $<0.001$ & $-2.36(-4.25,-0.46)$ & 0.015 \\
\hline Neutrophil to lymphocyte ratio & $0.44(-3.28,4.17)$ & 0.814 & - & \\
\hline \multicolumn{5}{|l|}{ Medications } \\
\hline Number of anti-hypertensive drugs & $-0.22(-1.03,0.59)$ & 0.595 & - & \\
\hline ACEi or ARB use $(\%)$ & $-0.84(-3.05,1.36)$ & 0.452 & - & \\
\hline
\end{tabular}

Abbreviations: BMI, body mass index; COPD, chronic obstructive pulmonary disease; MAP, mean arterial pressure; eGFR, estimated glomerular filtration rate; LDL, low-density lipoprotein cholesterol; ACEi, angiotensin-converting enzyme inhibitor; ARB, angiotensin II receptor blocker. 


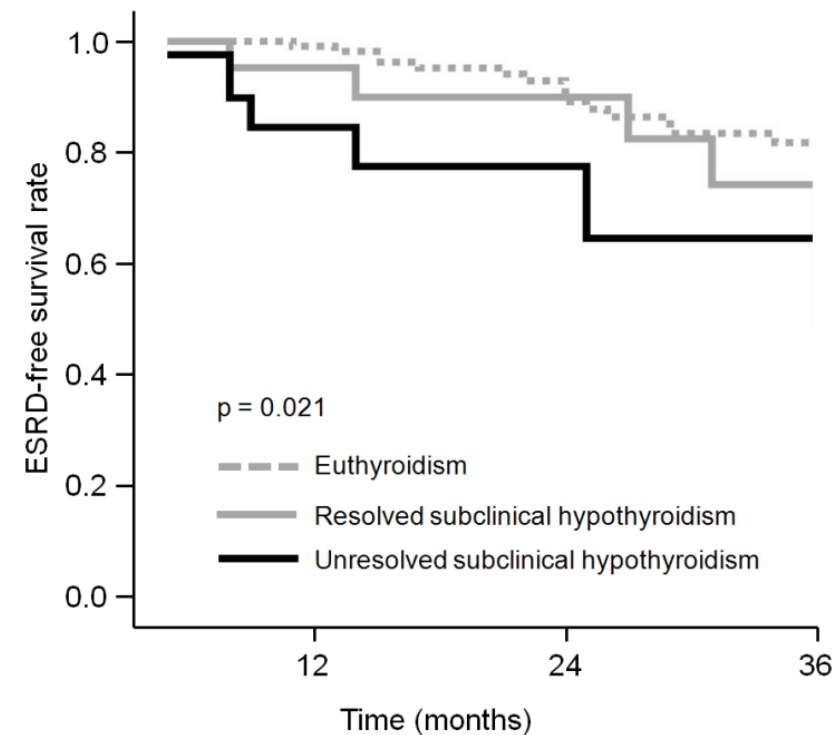

Figure 2. Comparison of ESRD-free survival curves between CKD patients with different thyroid status. The patients with unresolved subclinical hypothyroidism revealed significantly lower ESRD-free survival rate than that of euthyroid patients.

\section{Discussion}

The importance of understanding the impact of thyroid dysfunction on renal function is highlighted by recent studies indicating that subclinical hypothyroidism is common in patients with CKD (16). In the present study, the rate of renal function decline was not more rapid in patients who resolved their subclinical hypothyroidism than in euthyroid CKD patients. However, half the CKD patients with subclinical hypothyroidism did not normalize thyroid function, and unresolved subclinical hypothyroidism was significantly associated with a more rapid decline in renal function. In addition, we demonstrated that unresolved subclinical hypothyroidism was an independent factor contributing to the rate of eGFR decline, and that these individuals had a higher risk of progression to ESRD.

We demonstrated that the baseline TSH value was significantly higher in patients with unresolved subclinical hypothyroidism than in patients who resolved their subclinical hypothyroidism. In addition, patients who eventually progressed to overt hypothyroidism had an average baseline TSH of $10.06 \pm$ $5.39 \mu \mathrm{IU} / \mathrm{ml}$, significantly higher than that of the patients with persistent subclinical hypothyroidism (data not shown, $p=0.032$ ). These findings suggest that the baseline TSH value determined whether subclinical hypothyroidism spontaneously normalized or progressed to overt hypothyroidism. Therefore, baseline TSH values could be a useful indicator of the transition of subclinical hypothyroidism in patients with CKD.
In previous reports, the incidence of subclinical hypothyroidism is gradually increased with progressively lower GFR in patients with CKD $(1,16)$. Increased TSH level is a diagnostic marker for subclinical hypothyroidism, and there is a significant inverse correlation between eGFR and TSH levels in patients with subclinical hypothyroidism (16-18). However, these cross-sectional studies are limited in their ability to establish causal or temporal relationships between subclinical hypothyroidism and renal function, and could not determine the potential adverse effects on CKD progression. In the present study, we further confirmed that baseline TSH values were associated with unresolved hypothyroidism during follow-up, which was independently predictive for rapid renal function decline. These findings strengthen the clinical significance of TSH values and subclinical hypothyroidism in CKD progression, and suggest practical necessity to evaluate the thyroid function in patients with CKD.

Our study demonstrated that unresolved subclinical hypothyroidism was associated with progression to ESRD and that overt hypothyroidism developed in six (14.6\%) patients. The development of overt hypothyroidism was thought to have several effects that contribute to kidney dysfunction. Hypothyroidism is associated with preglomerular vasoconstriction, decreased cardiac output and decreased circulating blood volume, which lead to decreased renal perfusion (19-21). In subclinical hypothyroidism, inflammation, cardiac dysfunction and endothelial dysfunction is known to be more prevalent than in euthyroidism $(8,22-24)$. However, unresolved subclinical hypothyroidism patients did not show higher level of hsCRP and the neutrophil to lymphocyte ratio in the present study. To explore the exact mechanism of renal function decline in unresolved subclinical hypothyroidism patients, further complete investigations are needed particularly in cardiac and endothelial dysfunction.

A recent study indicated that L-thyroxine supplementation not only preserved renal function but also prevented progression to ESRD in CKD patients with subclinical hypothyroidism $(17,18)$. However, there are no guidelines for thyroid hormone therapy in CKD patients. Our study demonstrated that half the CKD patients with subclinical hypothyroidism spontaneously reverted to a euthyroid state, and that these patients showed a similar rate of eGFR decline/year to those patients who were euthyroid at baseline. In addition, the adverse impact of unresolved subclinical hypothyroidism on renal function decline was more remarkable in patients with CKD stage 3 than in patients with CKD stage 4 and was greater in patients with proteinuria $<0.3 \mathrm{~g} /$ day than 
in patients with proteinuria $0.3-3 \mathrm{~g} /$ day or proteinuria $>3 \mathrm{~g} /$ day. These findings suggest that hormone replacement is of little benefit in patients with resolved subclinical hypothyroidism, but that unresolved subclinical hypothyroidism could be an indication for thyroid hormone treatment, which might be more beneficial in patients with better renal function and lower proteinuria.

Our study had some limitations. First, it was a retrospective medical record-based study. Second, we did not investigate the levels of anti-thyroid peroxidase antibody, which allows the stratification for the resolution of subclinical hypothyroidism. Third, this study could not identify the appropriate waiting time to allow normalization of subclinical hypothyroidism. Finally, the relatively small sample size limited our ability to identify the significance of unresolved subclinical hypothyroidism in patients with CKD stage 2 and to differentiate the rate of CKD progression between patients with overt hypothyroidism and patients with persistent subclinical hypothyroidism. Therefore, future studies should prospectively evaluate the natural course of subclinical hypothyroidism in larger numbers of CKD patients.

In conclusion, half the CKD patients with subclinical hypothyroidism did not revert to normal thyroid function. Those who did resolve their subclinical hypothyroidism did not show a more rapid decline in renal function than euthyroid CKD patients. However, unresolved subclinical hypothyroidism was independently associated with rapid renal function decline and had a greater risk of progression to ESRD.

\section{Supplementary Material}

Table S1 - Table S2.

http://www.medsci.org/v11p0052s1.pdf

\section{Abbreviations}

CKD: chronic kidney disease; eGFR: estimated glomerular filtration rate; TSH: serum thyrotropin, BMI: body mass index; COPD: chronic obstructive pulmonary disease; MAP: mean arterial pressure; LDL: low-density lipoprotein; hsCRP: high sensitivity C-reactive protein; LV: left ventricular; EF: ejection fraction; ESRD: end-stage renal disease.

\section{Acknowledgements}

This study was supported by the Basic Science Research Program of the National Research Foundation of Korea (NRF) funded by the Ministry of Education, Science and Technology (2012R1A1A1009690).

\section{Competing Interests}

The authors have declared that no competing interest exists.

\section{References}

1. Lo JC, Chertow GM, Go AS, Hsu CY. Increased prevalence of subclinical and clinical hypothyroidism in persons with chronic kidney disease. Kidney Int 2005;67:1047-52.

2. Asvold BO, Bjøro T, Vatten LJ. Association of thyroid function with estimated glomerular filtration rate in a population-based study: the HUNT study. Eur J Endocrinol 2011;164:101-5.

3. Vargas F, Moreno JM, Rodríguez-Gómez I, Wangensteen R, Osuna A, Alvarez-Guerra M, García-Estañ J. Vascular and renal function in experimental thyroid disorders. Eur J Endocrinol 2006;154:197-212.

4. Karanikas G, Schütz M, Szabo M, Becherer A, Wiesner K, Dudczak R, Kletter K. Isotopic renal function studies in severe hypothyroidism and after thyroid hormone replacement therapy. Am J Nephrol 2004;24:41-5.

5. Mooraki A, Broumand B, Neekdoost F, Amirmokri P, Bastani B. Reversible acute renal failure associated with hypothyroidism: report of four cases with a brief review of literature. Nephrology (Carlton) 2003;8:57-60.

6. Kreisman SH, Hennessey JV. Consistent reversible elevations of serum creatinine levels in severe hypothyroidism. Arch Intern Med 1999;159:79-82.

7. Enia G, Panuccio V, Cutrupi S, Pizzini P, Tripepi G, Mallamaci F, Zoccali C. Subclinical hypothyroidism is linked to micro-inflammation and predicts death in continuous ambulatory peritoneal dialysis. Nephrol Dial Transplant 2007;22:538-44.

8. Chen HS, Wu TE, Jap TS, Lu RA, Wang ML, Chen RL, Lin HD. Subclinical hypothyroidism is a risk factor for nephropathy and cardiovascular diseases in Type 2 diabetic patients. Diabet Med 2007;24:1336-44.

9. Somwaru LL, Rariy CM, Arnold AM, Cappola AR. The natural history of subclinical hypothyroidism in the elderly: the cardiovascular health study. J Clin Endocrinol Metab 2012;97(6):1962-9.

10. Díez JJ, Iglesias P. Spontaneous subclinical hypothyroidism in patients older than 55 years: an analysis of natural course and risk factors for the development of overt thyroid failure. J Clin Endocrinol Metab 2004;89(10):4890-7.

11. Levey AS, Bosch JP, Lewis JB, Greene T, Rogers N, Roth D. A more accurate method to estimate glomerular filtration rate from serum creatinine: a new prediction equation. Modification of Diet in Renal Disease Study Group. Ann Intern Med 1999;130:461-70.

12. National Kidney Foundation. K/DOQI clinical practice guidelines for chronic kidney disease: evaluation, classification, and stratification. Am J Kidney Dis 2002;39(2 Suppl 1):S1-266.

13. Okyay GU, Inal S, Oneç K, Er RE, Paşaoğlu O, Paşaoğlu H, Derici U, Erten Y. Neutrophil to lymphocyte ratio in evaluation of inflammation in patients with chronic kidney disease. Ren Fail 2013; 35: 29-36.

14. Chen SC, Su HM, Hung CC, Chang JM, Liu WC, Tsai JC, Lin MY, Hwang $\mathrm{SJ}$, Chen HC. Echocardiographic parameters are independently associated with rate of renal function decline and progression to dialysis in patients with chronic kidney disease. Clin J Am Soc Nephrol 2011; 6:2750-8.

15. Devereux RB, Alonso DR, Lutas EM, Gottlieb GJ, Campo E, Sachs I, Reichek N. Echocardiographic assessment of left ventricular hypertrophy: comparison to necropsy findings. Am J Cardiol 1986; 57:450-8.

16. Chonchol M, Lippi G, Salvagno G, Zoppini G, Muggeo M, Targher G. Prevalence of subclinical hypothyroidism in patients with chronic kidney disease. Clin J Am Soc Nephrol 2008;3:1296-300.

17. Shin DH, Lee MJ, Kim SJ, Oh HJ, Kim HR, Han JH, Koo HM, Doh FM, Park JT, Han SH, Yoo TH, Kang SW. Preservation of renal function by thyroid hormone replacement therapy in chronic kidney disease patients with subclinical hypothyroidism. J Clin Endocrinol Metab 2012; 97: 2732-40.

18. Shin DH, Lee MJ, Lee HS, Oh HJ, Ko KI, Kim CH, Doh FM, Koo HM, Kim HR, Han JH, Park JT, Han SH, Yoo TH, Kang SW. Thyroid hormone replacement therapy attenuates the decline of renal function in chronic kidney disease patients with subclinical hypothyroidism. Thyroid 2013;23:654-61.

19. Crowley WF Jr, Ridgway EC, Bough EW, Francis GS, Daniels GH, Kourides IA, et al. Noninvasive evaluation of cardiac function in hypothyroidism. Response to gradual thyroxine replacement. N Engl J Med 1977;296:1-6.

20. Mariani LH, Berns JS. The renal manifestations of thyroid disease. J Am Soc Nephrol 2012;23:22-6. 
21. Zimmerman RS, Ryan J, Edwards BS, Klee G, Zimmerman D, Scott N, Burnett JC Jr. Cardiorenal endocrine dynamics during volume expansion in hypothyroid dogs. Am J Physiol 1988;255:R61-6.

22. Villabona C, Sahun M, Roca M, Mora J, Gómez N, Gómez JM, Puchal R, Soler J. Blood volumes and renal function in overt and subclinical primary hypothyroidism. Am J Med Sci 1999;318: 277-80.

23. Kang EW, Nam JY, Yoo TH, Shin SK, Kang SW, Han DS, Han SH. Clinical implications of subclinical hypothyroidism in continuous ambulatory peritoneal dialysis patients. Am J Nephrol 2008;28:908-13.

24. Cikim AS, Oflaz H, Ozbey N, Cikim K, Umman S, Meric M, Sencer E, Molvalilar S. Evaluation of endothelial function in subclinical hypothyroidism and subclinical hyperthyroidism. Thyroid 2004;14:605-9. 